\title{
Erratum to: China Satellite Navigation Conference (CSNC) 2016 Proceedings: Volume III
}

\author{
Jiadong Sun, Jingnan Liu, Shiwei Fan and Feixue Wang
}

\section{Erratum to: \\ J. Sun et al. (eds.), China Satellite Navigation Conference (CSNC) 2016 Proceedings: Volume III, Lecture Notes in Electrical Engineering 390, DOI 10.1007/978-981-10-0940-2}

The book was inadvertently published without including many changes in Chapters 21,25 , and 45 . The changes included language enhancements, capitalization changes, and addition in affiliation the same has been incorporated and the chapter and the erratum book has been updated.

\section{The updated original online version for this book can be found at} DOI 10.1007/978-981-10-0940-2

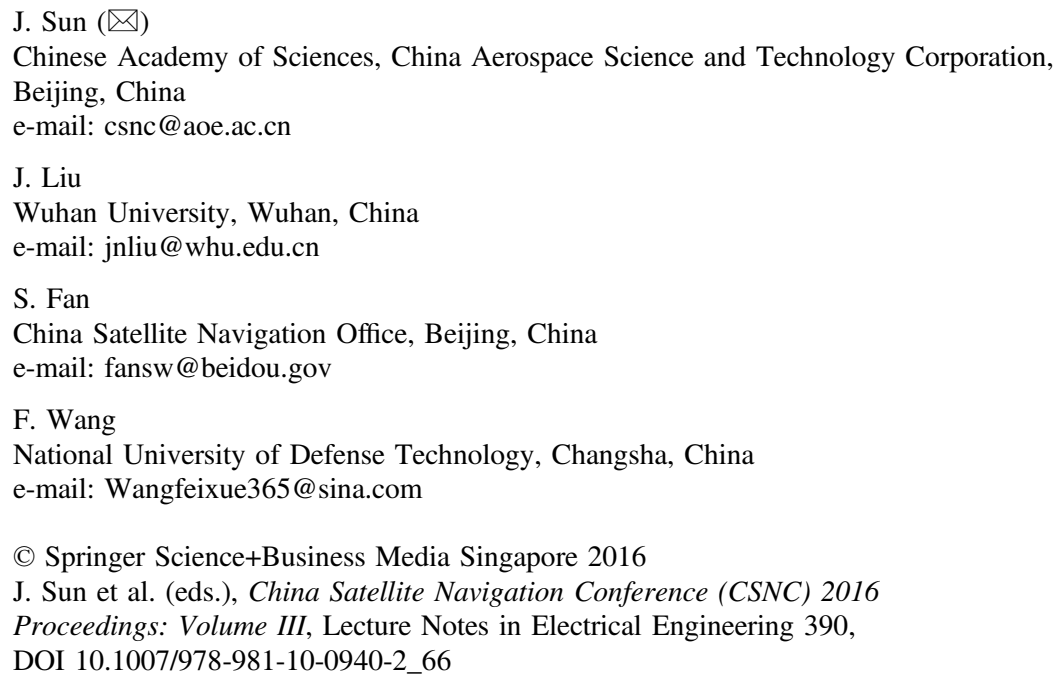

